\title{
Prostacyclin in Vascular Diseases - Recent Insights and Future Perspectives -
}

\author{
Jun-ichi Kawabe, MD*; Fumitaka Ushikubi, MD**; Naoyuki Hasebe, MD*,†
}

\begin{abstract}
Prostacyclin $\left(\mathrm{PGl}_{2}\right)$ is one of the important vascular prostanoids, the effects of which counteract those of thromboxane ( $\mathrm{TX}_{2}$ ), and these 2 prostanoids provide an important balance in cardiovascular homeostasis. The clinical experience of COX-2 selective inhibitors having unexpected adverse effects in patients with cardiovascular risk has opened up a debate about the role of COX-2-derived prostanoids in vascular pathophysiology. $\mathrm{PGl}_{2}$ is a major anti-atherogenic prostanoid produced by COX-2 in vascular cells, including endothelial and vascular smooth muscle cells. The balance between COX-2-derived PGI2, COX-1-derived TXA2, and other COX-2-mediated atherogenic prostanoids is a crucial factor in determining pathophysiological outcomes. Recent studies using stable $\mathrm{PGl}_{2}$ analogs and genetically deficient mice have revealed novel effects of $\mathrm{PGl}_{2}$ on its target cells, such as endothelial and endothelial progenitor cells. The role $\mathrm{PGI}_{2}$ in the physiology and pathophysiology of vascular diseases is reviewed and the recent findings linking $\mathrm{PGI}_{2}, \mathrm{COX}-2$ and atherothrombosis are summarized. (Circ J 2010; 74: 836-843)
\end{abstract}

Key Words: Atherosclerosis; Cyclooxygenase; Endothelial progenitor cells; Prostacyclin

$\mathbf{P}$ rostanoids are family of bioactive lipid mediators that are formed by cyclooxygenase (COX) from arachidonic acid (AA) contained in the cell membrane of all cells of the body. They are involved in numerous physiological activities, including platelet aggregation, vasorelaxation and vasoconstriction, local inflammatory response and leukocyte-endothelial cell adhesion. ${ }^{1,2}$ In this context, prostanoids modulate the pathogenesis of vascular diseases, such as thrombosis and atherosclerosis, in which inflammation has an important role in all the phases of progression, from the initial formation of the early plaque to the rupture of advanced plaques. ${ }^{3}$ It was believed that inflammatory-inducible COX-2 might be an ideal anti-inflammatory therapeutic target, but the clinical experience of some COX-2 selective inhibitors causing unexpected adverse effects in patients with potential cardiovascular risk has opened the debate about the role of COX-2-derived prostanoids in vascular pathophysiology and the benefits and risk of using COX-2 inhibitors in cardiovascular diseases.

The role of COX-2 in atherothrombosis appears to be quite complex, as it is an intermediate enzyme in the cascade of AA and generates not only pro-inflammatory but also anti-inflammatory prostanoids, according to the type of coexpressed downstream prostanoid synthases in each tissue or cell type. ${ }^{4,5} \mathrm{It}$ is recognized that prostacyclin $\left(\mathrm{PGI}_{2}\right)$ is a key player in the complicated COX-prostanoids cascade in cardiovascular diseases, because PGI is a major anti-atherogenic prostanoid produced by $\mathrm{COX}-2$, and counteracts platelet- derived thromboxane $\left(\mathrm{TXA}_{2}\right)$ and other COX-2 mediated atherogenic prostanoids. ${ }^{6,7}$ Recent studies using stable $\mathrm{PGI}_{2}$ analogs and genetically deficient mice have revealed the novel effects of PGI 2 on target cells, such as endothelial cells and endothelial progenitor cells (EPCs), which have crucial functions in the pathogenesis of atherosclerosis. Accordingly, we review the role PGI 2 in the physiology and pathophysiology of vascular diseases, summarizing the recent findings linking PGI, COX-2, and atherothrombosis.

\section{Effects of PGI2 Through Dual Signal Pathways in the Cardiovascular System}

PGI $_{2}$ is thought to be one of the most important prostanoid in regulating the homeostasis of the cardiovascular system. ${ }^{6,7}$ Platelet precursors, megakaryocytes, as well as vascular smooth muscle cells (VSMCs) are the major target cells of PGI2. PGI is a potent vasodilator, and an inhibitor of platelet aggregation, leukocyte adhesion, and VSMC proliferation. ${ }^{1,2}$ These actions of $\mathrm{PGI}_{2}$ are mediated through specific cell surface receptors, known as IP. IP is a 7-membrane spanning G-protein coupled receptor that generates cyclic AMP (cAMP) to mediate its physiological effects. ${ }^{8}$ Peroxisome proliferator activated receptors (PPARs), including $\alpha, \delta$ and $\gamma$, are members of the superfamily of nuclear receptors with activities relevant to broad aspects of cardiovascular biology. ${ }^{9,10}$ Accumulating evidence has revealed that the effects of PGI 2 on vasculature are mediated by the PPAR $\delta$ pathway, in addition

Received March 2, 2010; accepted March 26, 2010; released online April 15, 2010

*Departments of Cardiovascular Regeneration and Innovation, **Department of Pharmacology and Department of Internal Medicine, Cardiovascular, Respiratory and Neurology Division, Asahikawa Medical College, Asahikawa, Japan

Mailing address: Jun-ichi Kawabe, MD, Department of Cardiovascular Regeneration and Innovation, Asahikawa Medical College,

2-1-1-1 Midorigaoka-higashi, Asahikawa 078-8510, Japan. E-mail: kawabeju@asahikawa-med.ac.jp

ISSN-1346-9843 doi:10.1253/circj.CJ-10-0195

All rights are reserved to the Japanese Circulation Society. For permissions, please e-mail: cj@j-circ.or.jp 


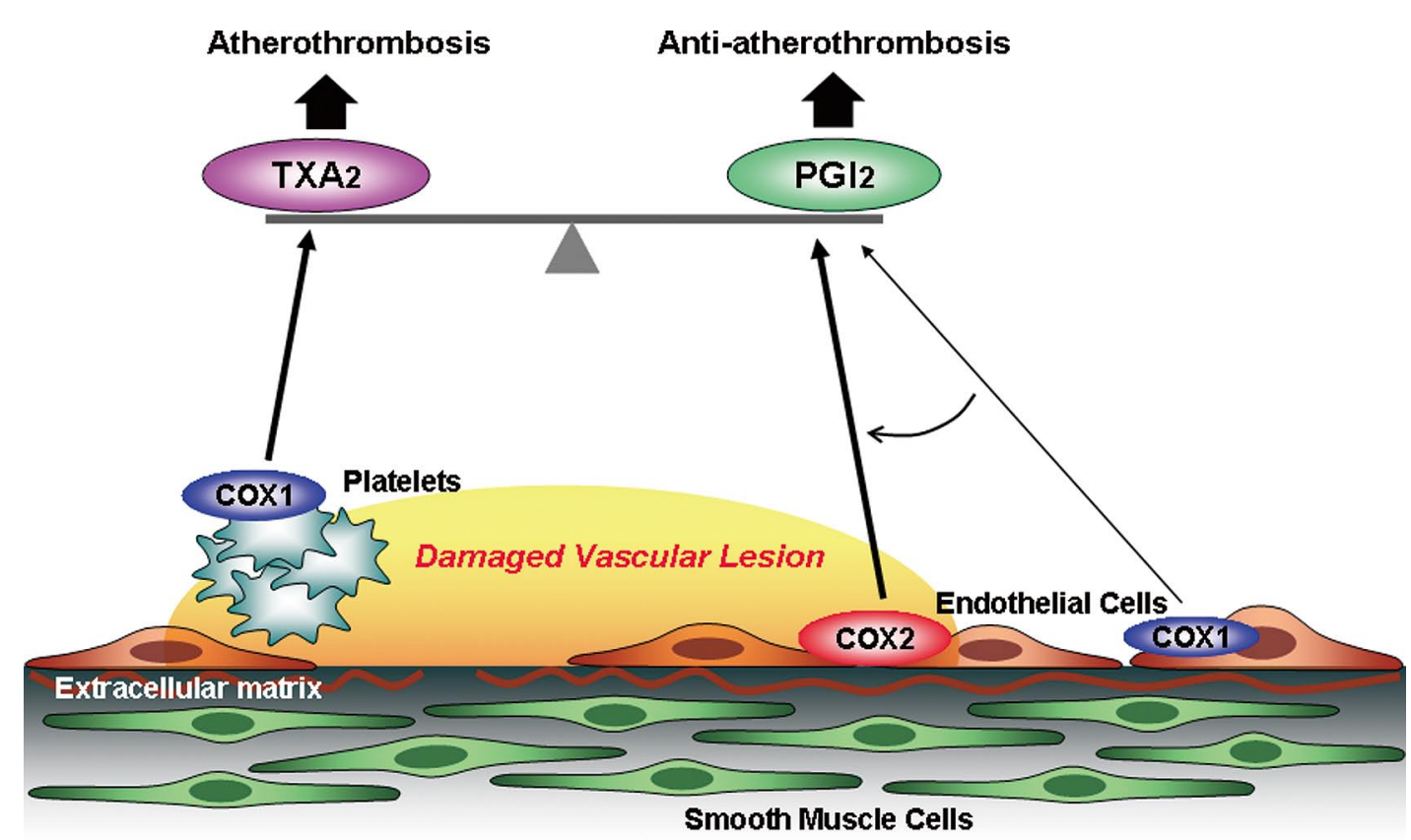

Figure 1. The balance hypothesis between COX-1/TXA2 and COX-2/PGI 2 in vascular lesions. In the steady state, the endothelial production of $\mathrm{PGI}_{2}$ is predominantly dependent on COX-1. However, in response to vascular damage, expression of COX-2 is induced in endothelial cells to advance the formation of $\mathrm{PGl}_{2}$, opposing the enhanced atherogenic effects of $T X A_{2}$, which is synthesized through COX-1 by platelets. Accordingly, progression of atherothrombogenesis is dependent on the ratio or balance between COX-1-derived $\mathrm{TXA}_{2}$ by platelets and endothelial COX-2-mediated $\mathrm{PGI}_{2}$ production. COX, cyclooxygenase; $\mathrm{PGI}_{2}$, prostaglandin I2 (prostacyclin); TXA2, thromboxane.

to the classical IP-cAMP signal pathway. ${ }^{11}$

The role of PPAR $\delta$ in VSMCs is somewhat controversial. It has been shown that the expression of PPAR $\delta$ is enhanced in proliferative rat VSMCs, and overexpression of PPAR $\delta$ in VSMCs increased proliferation. ${ }^{12}$ In contrast, activation of PPAR $\delta$ has induced cell cycle arrest in VSMCs and inhibited their proliferation and migration. ${ }^{13}$ Recent works suggest that PPAR $\delta$ activation by $\mathrm{PGI}_{2}$ may induce endothelial proliferation and angiogenesis. ${ }^{14,15} \mathrm{PGI}_{2}$ also protected endothelial cells from $\mathrm{H}_{2} \mathrm{O}_{2}$-induced apoptosis through inducing PPAR $\delta$-mediated 14-3-3 protein expression, which prevents the action of the pro-apoptotic factor, Bad. ${ }^{16}$ It should be noted that most of these effects were observed using stable $\mathrm{PGI}_{2}$ analogs. PGI 2 analogs such as iloprost and carba-prostacylcin, but not cicaprost, act not only on IP receptors, but also on PPAR $\delta$ to induce proliferation and angiogenesis..$^{14}$ However, more recently, Tsai et al reported that contractile phenotype modulation (differentiation) of human VSMCs was induced through the activation of PPAR $\alpha / \delta$ by endogenous endothelial PGI $2 .^{17}$

\section{Role of $\mathrm{PGI}_{2}$ in Atherosclerosis}

$\mathrm{PGI}_{2}$ may have a protective effect in the atherogenic process by limiting platelet activation, leukocyte adhesion to the endothelium and VSMCs proliferation in plaque. ${ }^{18,19}$ In accordance with this idea, a PGI2 stable analog, beraprost, or PGI 2 synthase (PGIS) gene transfer inhibit neointimal formation in animal models of arterial injury. ${ }^{20,21}$ In a clinical study, the IP variant (R212C), which was defective in cAMP production, was closely linked to disease severity and adverse car- diovascular events in patients with cardiovascular diseases. ${ }^{22}$ The cardiovascular effects of $\mathrm{PGI}_{2}$ contrast with those of TXA2, which causes platelet aggregation, vasoconstriction, and vascular proliferation. ${ }^{23}$ Accordingly, $\mathrm{PGI}_{2}$ and $\mathrm{TXA}_{2}$ are thought to be two of the most important prostanoids in regulating the homeostasis of the cardiovascular system. ${ }^{6,7}$

Mice models of genetic prostanoid-receptor deficient have given valuable information about the function of prostanoids in cardiovascular diseases. Although IP-deficient mice had normal blood pressure and matured normally without suffering from spontaneous thrombosis, platelet aggregation and VSMC proliferation in response to vascular injury were enhanced compared with control littermates. ${ }^{6,24}$ Mice lacking IP also had aggravated atherogenesis with enhanced platelet activation and increased adhesion of leukocytes on the vessel walls in both the low-density lipoprotein (LDL)-receptor model and apoE knockout models. ${ }^{25,26}$ These findings suggest that PGI2 plays a significant role in atherosclerosis only in response to endothelial damage and not in the basal systemic circulation. In contrast to IP-deficient mice, mice lacking the TXA2 specific receptor, TP, exhibited an increase in bleeding tendency and decrease in platelet aggregation, confirming the role of TXA 2 in those activities. ${ }^{27}$ Because TXA 2 is a mitogen of VSMCs, TP-knockout mice have decreased VSMCs proliferation and platelet activation in response to vascular injury, ${ }^{6}$ and a significant delay in atherogenesis is induced, compared with mice deficient in apoE alone. ${ }^{26}$ Those results indicate that TXA2 promotes, whereas $\mathrm{PGI}_{2}$ prevents, the initiation and progression of atherogenesis. Simultaneous deletion of both TP and IP abrogated both of the augmented responses to vascular injury, and the mice did not show any 
difference in vascular remodeling compared with wild-type controls. ${ }^{6}$ Because of this contradictory action of PGI 2 and $\mathrm{TXA}_{2}$, many aspects of cardiovascular disease have been explained by alterations in the balance between $\mathrm{PGI}_{2}$ and $\mathrm{TXA}_{2}$ during the interactions between platelets and the vessel wall (Figure 1). ${ }^{28,29}$

\section{Lessons From Clinical Experience With COX-2 Selective Inhibitors}

It has been traditionally recognized that inducible COX-2 is responsible for prostanoid production associated with inflammation, and COX-1 is important for the prostanoids with "housekeeping" functions, such as gastric cytoprotection.1,2 The ability of classical non-steroidal anti-inflammatory drugs (NSAIDs), the non-selective COX inhibitors, to inhibit COX-2 activity may explain their therapeutic anti-inflammatory effects, whereas inhibition of COX-1 may account for some of the adverse effects such as gastrointestinal and renal toxicity. According to this simple hypothesis, therefore, COX-2 selective inhibitors (coxibs) were expected to be ideal anti-inflammatory drugs, minimizing gastrointestinal toxicity. ${ }^{30}$ Furthermore, based on the hypothesis that atherosclerosis is an inflammatory disease, it was proposed that selective inhibition of COX-2 might have anti-atherogenic effects. However, clinical studies have indicated that there is an increased cardiovascular risk in individuals taking some of the coxibs. ${ }^{31,32}$

\section{Balance Between COX-1-Derived TXA2 and COX-2-Derived $\mathrm{PGI}_{2}$}

The undesirable effects of coxibs have been explained by the $\mathrm{TXA}_{2}$ and $\mathrm{PGI}_{2}$ imbalance theory by which selective inhibition of COX-2 leads to a reduction in the production of the anti-atherogenic $\mathrm{PGI}_{2}$ while production of the atherogenic TXA2, mostly COX-1-dependent, remains unaffected, ${ }^{33}$ although some studies argue about this theory (Figure 1). ${ }^{34}$ This theory is based on the finding that endothelial PGI2 production is mediated through $\mathrm{COX}-2$ activation. $\mathrm{PGI}_{2}$ is the predominant COX-2 product of the vascular endothelium, and administration of coxibs to healthy subjects reduced $\mathrm{PGI}_{2}$ metabolites in urine without affecting TXA2 metabolites. ${ }^{35}$ Although COX-1 is dominantly expressed in endothelial cells under static conditions, ${ }^{36,37} \mathrm{COX}-2$ expression and COX-2dependent $\mathrm{PGI}_{2}$ production are increased in vitro by laminar shear stress, thromobin, oxidized LDLs or hypoxia. ${ }^{38-41} \mathrm{COX}$ 2 has been reported in low levels, or not detected, in normal human arteries, and COX-2 appears predominantly expressed in endothelial cells overlying vascular lesions in the carotid, aortic, or coronary artery districts..$^{36,37,42}$ Notably, PGIS gene transfer modulated COX-2-derived $\mathrm{PGI}_{2}$ synthesis and inhibited neointimal formation in injured rat vascular walls, indicating that COX-2 is functionally linked with PGIS to produce $\mathrm{PGI}_{2}$ and regulate vascular remodeling in the injured artery. ${ }^{43}$ These findings suggest that COX-2 is a key isoenzyme for $\mathrm{PGI}_{2}$ production, especially in vascular injury, competing with anti-atherogenic TXA2 (Figure 1).

\section{COX-2-Derived $\mathrm{PGI}_{2}$ and Other Atherogenic Prostanoids in Atherosclerosis}

The $\mathrm{PGI}_{2}$ and TXA 2 imbalance theory shows the clear involvement of endothelial COX-2-derived $\mathrm{PGI}_{2}$ in cardiovascular diseases. Nevertheless, the net effect of COX-2 expression and COX-2-derived prostanoids in the different phases of atherogenesis remains controversial. Adhesion of circulating monocytes and macrophages to activated endothelial cells appears to be a critical early event in atherosclerotic lesions. ${ }^{44}$ COX-2 is localized predominantly in macrophages within the plaque lesions, ${ }^{37,45}$ and increased COX-2 expression is paralleled by increased levels of $\mathrm{PGE}_{2}{ }^{45,46} \mathrm{PGE}_{2}$ is considered to be one of the most atherogenic prostanoids, mediating the progression of atherogenesis through several mechanisms, such as induction of other pro-inflammatory mediators and adhesion molecules, facilitating migration of macrophages and other immune cells. ${ }^{36}$ More recently, it was reported that COX-2/PGE2 in macrophages mediates the susceptibility of plaques toward rupture by weakening the fibrous cap through the upregulation and activation of matrix metalloproteinase. ${ }^{47}$ In LDL-receptor deficient mice, COX-2 promoted early atherosclerotic lesion formation, and COX-2 inhibition reduced lesion formation. ${ }^{48}$ These observations suggest that selective inhibition of COX-2 might attenuate atherogenesis by inhibiting the production of pro-inflammatory prostanoids.

In addition to a pro-atherogenic role of inflammatory $\mathrm{COX}$ 2 , an atheroprotective role of endothelial $\mathrm{COX}-2 / \mathrm{PGI}_{2}$ production has been proposed. COX-2 related PGI2 synthesis by endothelial cells is increased by inflammatory cytokines, ${ }^{39,40}$ which also potentially induce $\mathrm{COX}-2$ and $\mathrm{PGE}_{2}$ synthesis in inflammatory cells. ${ }^{49,50}$ Therefore, endothelial COX-2 expression may represent a negative feedback mechanism triggered in part by pro-atherogenic/thrombotic stimuli by monocytes and macrophages (Figure 2). In atherosclerotic lesions, COX2-derived $\mathrm{PGI}_{2}$ production is observed in not only endothelial cells, but also other cells, such as VSMCs. ${ }^{51}$ Sphingosine-1phosphate (S1P) is a bioactive lysophospholipid present in plasma, and platelets are one of the main sources of S1P. ${ }^{52}$ $\mathrm{S} 1 \mathrm{P}$-induces $\mathrm{PGI}_{2}$ formation through COX-2 expression in endothelial and VSMCs. ${ }^{53}$ Interestingly, plasma S1P is accumulated in high-density lipoprotein (HDL). Accordingly, it is suggested that HDL-associated S1P is in part responsible for the beneficial anti-atherogenic effects of these lipoproteins through the upregulation of $\mathrm{PGI}_{2}$ in vascular cells. ${ }^{54}$ As regards COX-2-derived prostanoids, the balance of proatherogenic prostanoids, such as $\mathrm{PGE}_{2}$, from inflammatory cells and anti-atherogenic $\mathrm{PGI}_{2}$ from vascular cells could be a determinant factor in the pathogenesis of atherosclerosis (Figure 2). Indeed, PGI2 synthesis from the human aorta has been shown to be decreased as a function of progressing atherosclerotic lesions, and $\mathrm{PGE}_{2}$ increases in parallel. ${ }^{55}$ Accordingly, the beneficial or unfavorable effect of coxibs in atherogenesis is dependent upon the balance between these COX-2-derived prostanoids.

\section{Novel Role of $\mathrm{PGl}_{2}$ in the Vasculature}

Because of the fragility of prostanoids, it has been difficult to clarify their effects, especially in vivo. Stable PGI2 analogs such as beraprost, iloprost, and cicaprost have been developed and they mimic the biological properties of $\mathrm{PGI}_{2}$, such as activation of adenylyl cyclase and increasing the intracellular cAMP level through the activation of IP. ${ }^{56}$ Cicaprost is a unique PGI 2 analog that acts on the IP receptor only, whereas other $\mathrm{PGI}_{2}$ analogs also induce activation of the IP-independent PPAR $\delta$ pathway (see earlier). ${ }^{11}$ By using $\mathrm{PGI}_{2} / \mathrm{IP}$ signal system-stimulating chemicals or techniques of genetic manipulation, such as knockout animals and small RNA interference, various novel actions of $\mathrm{PGI}_{2}$ have been revealed. 


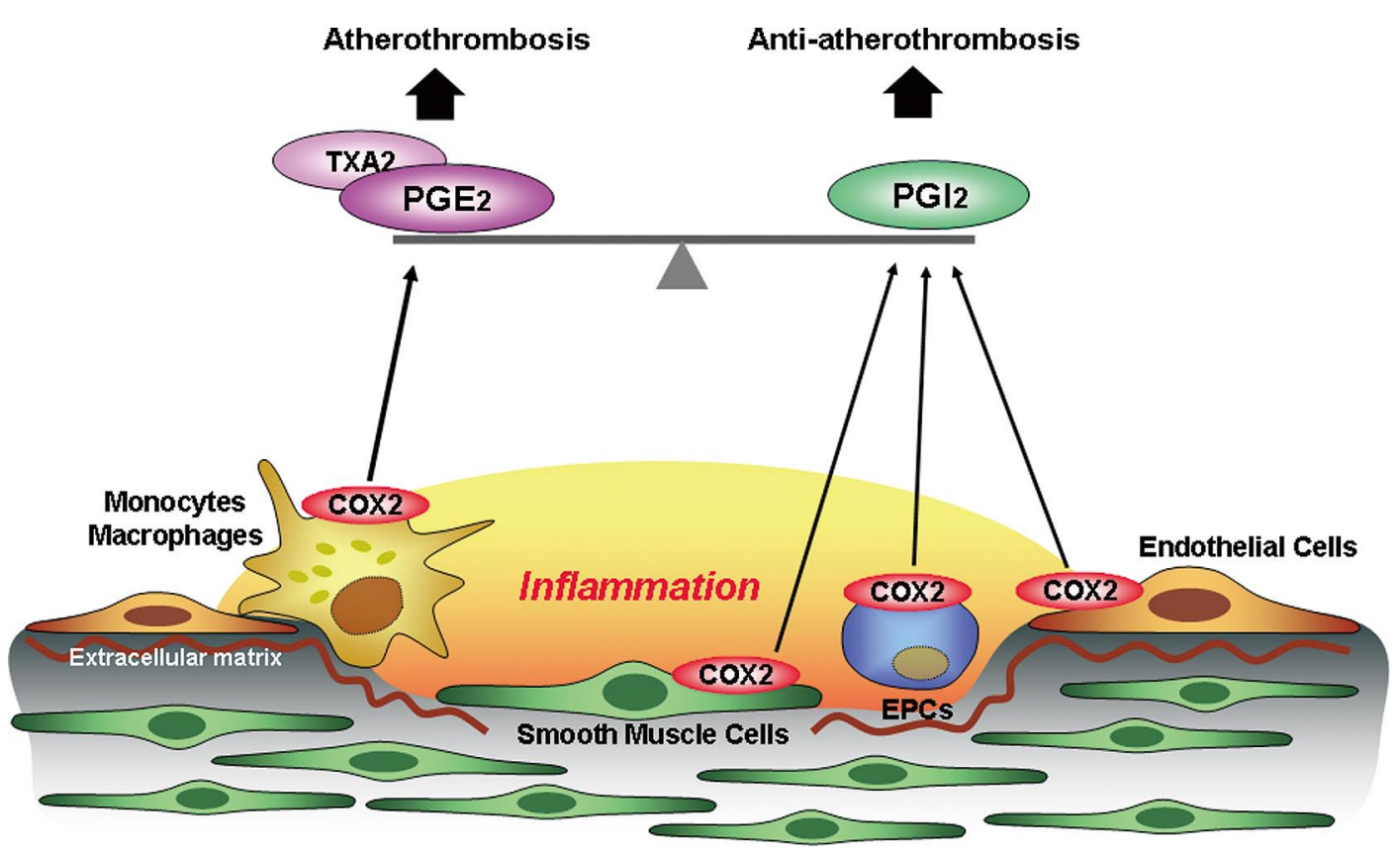

Figure 2. The balance between COX-2-derived atherogenic prostanoids and $\mathrm{PGI} 2$ within atherosclerotic lesions. Monocytes/ macrophages accumulate in atherosclerotic lesions, and release inflammatory factors, including atherogenic prostanoids such as PGE2 through COX-2 activation. COX-2 expression is induced in endothelial cells, vascular smooth muscle cells, and also in recruited endothelial progenitor cells (EPCs), thereby anti-atherogenic $\mathrm{PGI}_{2}$ is produced in all these cells as a compensatory effect against the enhanced inflammatory reaction. Although endothelial cells are the main source of $\mathrm{PGI}_{2}$ in the steady-state vasculature, recruited EPCs may be important PGI 2 -supplying cells in injured vascular walls, in which production of $P G l_{2}$ by the endothelium is limited. In addition to the balance between $\mathrm{TXA}_{2} / \mathrm{COX}-1$ and $\mathrm{PG} \mathrm{I}_{2} / \mathrm{COX}-2$, the ratio/balance of each prostanoid produced by COX-2 in different cell types is also important for the pathogenesis of atherosclerosis. Accordingly, COX-2 specific inhibitors may affect (ie, enhance or inhibit) the pathogenesis of atherosclerosis, depending on the balance of these prostanoids. COX, cyclooxygenase; $\mathrm{PGI}_{2}$, prostaglandin I2 (prostacyclin); TXA2, thromboxane.

\section{Angiogenesis and $\mathrm{PGI} 2$}

Angiogenesis, which is controlled by the balance between pro- and anti-angiogenic factors, has a role in the pathogenesis of several disorders, including cancer, chronic inflammatory diseases and ischemic diseases. Previous studies reported the anti-angiogenic function of NSAIDs, which were mediated mainly through COX-2 inhibition. ${ }^{57}$ Recently, there has been increasing evidence of the relationship existing between $\mathrm{PGI}_{2}$ and angiogenesis. ${ }^{57,58} \mathrm{PGI}_{2}$ is considered a key molecule linking the up- and downstream effects of pro-angiogenic factors. It has been reported that $\mathrm{PGI}_{2}$ induces the production of vascular endothelial growth factor (VEGF) in several cell types, including vascular cells, ${ }^{59-61}$ and also enhances the biological effects of pro-angiogenic factors. ${ }^{62}$ Transfection of the PGIS gene enhanced the efficiency of gene-transfection of pro-angiogenic factors, such as heparin growth factor (HGF), in animal models of peripheral ischemia. ${ }^{63,64}$ On the other hand, the synthesis of $\mathrm{PGI}_{2}$ in several cell types, including endothelial cells, is increased by pro-angiogenic factors such as VEGF. ${ }^{65-67}$

\section{Effects of $\mathrm{PGI}_{2}$ on Endothelial Cells}

It is known that IP is expressed on endothelial cells, but the effects of $\mathrm{PGI}_{2}$ on endothelial cells were not able to be clarified until stable $\mathrm{PGI}_{2}$ analog were developed. Recently, there have been studies indicating that PGI 2 analogs have protective functions against endothelial damage. Beraprost restored endothelial dysfunction in diabetic rats, accompanied by the induction of vascular HGF. ${ }^{68}$ Endothelial nitric oxide synthase (eNOS) is an important regulatory enzyme for endothelial functions, including vascular tone and cellular protection against oxidative stress. ${ }^{69}$ Interestingly, Niwano et al reported that beraprost increased the expression of eNOS through the cAMP pathway, proposing the existence of crosstalk between eNOS and PGI 2 within endothelial cells. ${ }^{70,71}$ Thus, the protective effects of PGI2 on endothelial cells might be mediated in part by the formation of NO. On the other hands, the vasorelaxant effects of $\mathrm{PGI}_{2}$ are widely considered to be endothelium-independent, via IP receptor-mediated cAMP accumulation in VSMCs. It has also been proposed that complex interactions between NO and cAMP in endothelial cells are involved in the endothelial-dependent vasorelaxant effects of $\mathrm{PGI}_{2}$.

\section{New Target Cells for PGI2; Endothelial Progenitor Cells (EPCs)}

Since EPCs were identified in $1997,{ }^{72}$ a growing body of evidence has outlined the key roles of circulating EPCs in vascular repair $^{73,74}$ and angiogenesis..$^{75,76}$ Once the vascular wall is injured or tissues suffer from ischemia, EPCs are mobilized to the peripheral blood and target on those sites, differentiating into endothelial cells and/or producing angiogenic growth factors, participating in their effects. However, the mechanisms underlying EPC-mediated functions are still 


\section{Anti-atherothrombotic \& Anti-ischemic Effects}

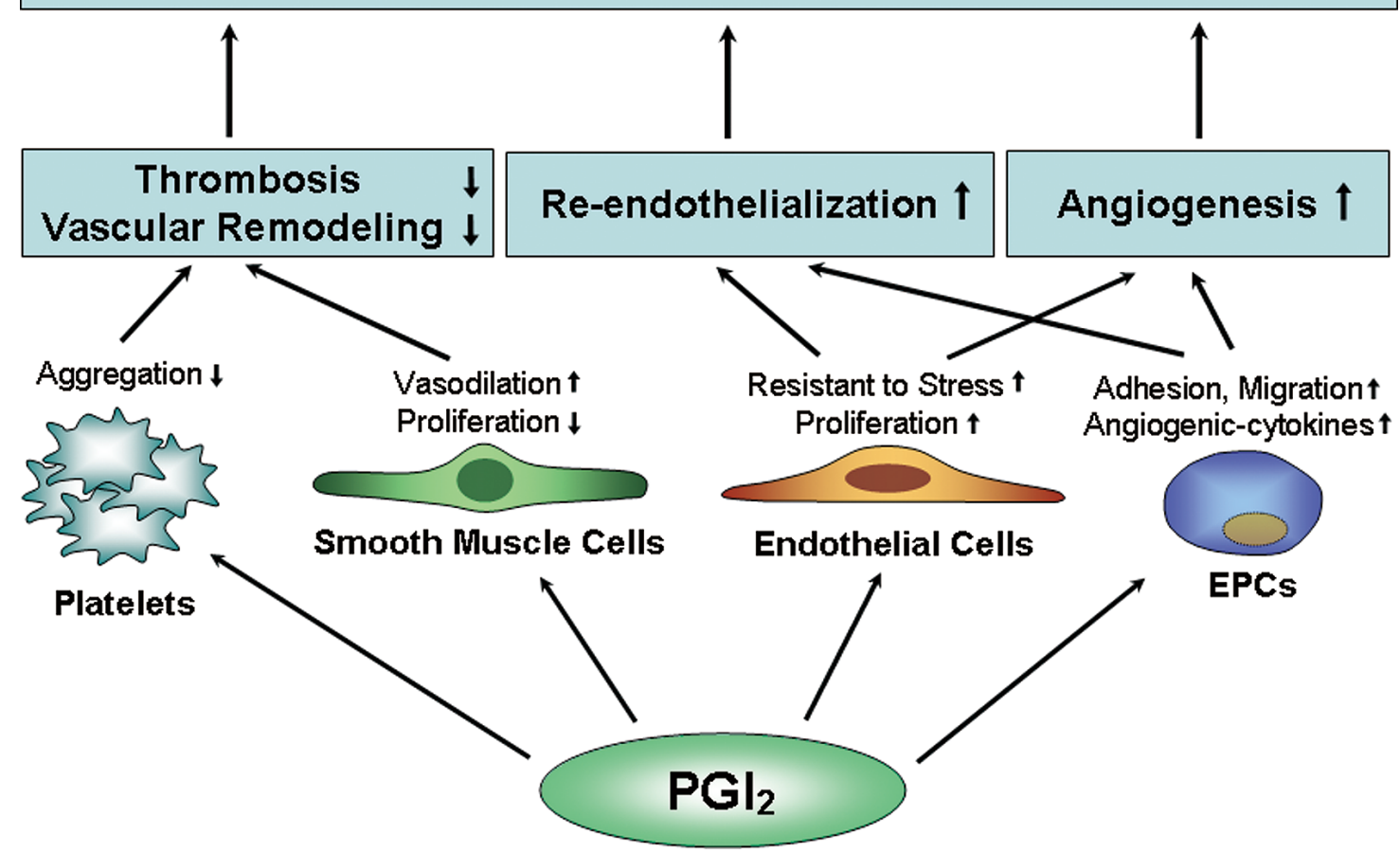

Figure 3. Classical and new effects of $P \mathrm{Fl}_{2}$ in cardiovascular diseases. $\mathrm{PGl}_{2}$ affects platelets and vascular smooth muscle cells to reduce platelet aggregation and induce vascular relaxation, respectively. $\mathrm{PG} \mathrm{I}_{2}$ also acts on endothelial cells and endothelial progenitor cells (EPCs), and may contribute to the repair of injured vascular walls and to angiogenesis. Although the anticoagulant activity of $\mathrm{PGI}_{2}$ seems to be mediated primarily by $\mathrm{PGI}_{2}$ receptor, IP, the effects of $\mathrm{PG} \mathrm{I}_{2}$ on the vasculature may be shared between the IP/cAMP and PPAR $\delta$ signal pathways. cAMP, cyclic AMP; PGI2, prostaglandin I2 (prostacyclin); PPAR, peroxisome proliferator activated receptor.

not clearly understood. Recent evidence suggests that bonemarrow-derived mononuclear cells (MNCs) or EPCs may contribute to the angiogenic or anti-atherogenic effects of PGI2. Beraprost increased capillary density in ischemic myocardium of rats, and attenuated infarct size, effects that were well associated with the increased number of EPCs in both the plasma and within the ischemic myocardium. ${ }^{77}$ Administration of beraprost enhanced the efficacy of therapeutic angiogenesis induced by autologous implantation of bonemarrow-derived MNCs in rabbit ischemic hindlimb tissues. ${ }^{78}$ Iloprost, a PGI 2 analog, increased the number of circulating EPCs in patients with critical limb ischemia. ${ }^{79}$ It is proposed that these $\mathrm{PGI}_{2}$ effects are mediated partly through the production of EPC-mobilizing factors. Indeed, dibutyl cAMP (DBcAMP), which accelerates vascularization in wound sites, induces the expression of VEGF and stromal-cell-derived factor, leading to the mobilization of EPCs from bone marrow. ${ }^{80}$

More recently, we and other group have reported that $\mathrm{PGI}_{2}$ has a direct effect on EPCs functions in an autocrine or paracrine manner, to mediate the beneficial effects of $\mathrm{PGI}_{2}$ in angiogenesis and repairing vascular walls. ${ }^{81,82}$ The EPCs were IP-expressing cells among bone-marrow-derived MNCs, and in vitro EPC functions (eg, adhesion to extracellular matrix and migration) were tightly regulated by the $\mathrm{PGI}_{2} / \mathrm{IP}$ pathway. ${ }^{82}$ In bone-marrow-transplanted mice, which lack IP selectively in bone marrow, EPCs were normally mobilized into peripheral blood in response to vascular injury. However, recruitment of EPCs to injured vascular walls was impaired, and subsequent neointimal formation was apparently enhanced. This worsened vascular remodeling was rescued by transplantation of exogenous intact wild-type EPCs, but not by IP-deleted EPCs. Thus, PGI influences EPC functions through the IP pathway. In contrast, He et al reported that intracellular $\mathrm{PGI}_{2}$ could stimulate the pro-angiogenic activities of EPCs through the PPAR $\delta$ pathway, but not through that of IP. ${ }^{81}$ Inactivation of either COX or PGIS decreased tube formation and cell proliferation of EPCs, which were rescued by treatment with iloprost or a selective PPAR $\delta$ agonist, but not by the selective $\mathrm{PGI}_{2}$ receptor, IP agonist, cicaprost.

As regard the anti-atherogenic effects of EPCs, it would be worthwhile knowing the function of EPCs as PGI2-supplying cells. In mouse EPCs isolated from bone marrow, or human EPCs outgrown from peripheral blood MNCs, a high level of COX-1 expression was observed in vitro under basal conditions, and $\mathrm{PGI}_{2}$ biosynthesis was mediated through COX-1 activation. ${ }^{81,82}$ Expression of COX-2 protein was almost undetectable, but increased after treatment with tumor necrosis factor- $\alpha$, and the level of COX-2-derived $\mathrm{PGI}_{2}$ by EPCs was apparently greater than that of human endothelial cells. ${ }^{81}$ Thus, it is proposed that recruited EPCs may play role as a $\mathrm{PGI}_{2}$-supplying cells, instead of endothelial cells in the injured vascular walls, in which endothelium is damaged 
or denuded from vascular walls (Figure 2). Alternatively, cytoprotective PGI2 released by EPCs may rescue damaged endothelial cells, and accelerate the regeneration of new endothelium in atherosclerotic lesions (Figure 3). ${ }^{82,83}$ In particular, paracrine effects of cytokines released by EPCs have also been proposed as a mechanism underlying the vasoprotective effects of EPCs. ${ }^{84,85}$

\section{Summary and Future Direction}

The clinical experience with coxibs promotes understanding of the role of COX-2-derived prostanoids in cardiovascular diseases. COX-2 contributes to the synthesis of not only proinflammatory prostanoids but also potent anti-atherogenic $\mathrm{PGI}_{2}$, and the balance between $\mathrm{PGI}_{2}$ and other atherogenic prostanoids is crucial for determining atherothrombotic pathological outcomes. In addition to endothelial cells, other vascular cells, including VSMCs and recruited EPCs, could be important sources of $\mathrm{PGI}_{2}$ within atherosclerotic lesions.

Experimental modifications of the $\mathrm{PGI}_{2} / \mathrm{IP}$ signal by genetic IP knockout or pharmacological agonist/antagonism have revealed the novel effects of $\mathrm{PGI}_{2}$ on target cells, such as endothelial cells and EPCs. This growing body of evidence outlines the mechanisms of the vasculoprotective role of $\mathrm{PGI}_{2}$, and effective clinical applications of $\mathrm{PGI}_{2}$ to vascular diseases could be further introduced. Particularly, EPCs provide a potential approach to vascular repair and angiogenesis. However, under pathological conditions, such as diabetes and aging, the functional capacities of EPCs appear to be impaired. ${ }^{86}$ In this regard, the regulatory role of $\mathrm{PGI}_{2}$ in EPC functions could be a new therapeutic strategy for cardiovascular diseases.

\section{Acknowledgments}

This work was supported in part by Grants-in-Aid for Scientific Research from the Ministry of Education, Culture, Sports, Science and Technology of Japan, and grants from Takeda Science Foundation, Akiyama \& Suhara Foundations, Japan.

\section{References}

1. Morita I. Distinct functions of COX-1 and COX-2. Prostaglandins Other Lipid Mediat 2002; 68/69: 165-175.

2. Hinz B, Brune K. Cyclooxygenase-2: 10 years later. J Pharmacol Exp Ther 2002; 300: 367-375.

3. Libby P. Inflammation in atherosclerosis. Nature 2002; 420: $868-$ 874.

4. Helliwell RJ, Adams LF, Mitchell MD. Prostaglandin synthases: Recent developments and a novel hypothesis. Prostaglandins Leukot Essent Fatty Acids 2004; 70: 101-113.

5. Ueno N, Takegoshi Y, Kamei D, Kudo I, Murakami M. Coupling between cyclooxygenases and terminal prostanoid synthases. Biochem Biophys Res Commun 2005; 338: 70-76.

6. Cheng Y, Austin SC, Rocca B, Koller BH, Coffman TM, Grosser $\mathrm{T}$, et al. Role of prostacyclin in the cardiovascular response to thromboxane A2. Science 2002; 296: 539-541.

7. Smyth EM, FitzGerald GA. Human prostacyclin receptor. Vitam Horm 2002; 65: 149-165.

8. Narumiya S, Sugimoto Y, Ushikubi F. Prostanoid receptors: Structures, properties, and functions. Physiol Rev 1999; 79: 1193-1226.

9. Brown JD, Plutzky J. Peroxisome proliferator-activated receptors as transcriptional nodal points and therapeutic targets. Circulation 2007; 115: 518-533.

10. Takano H, Komuro I. Peroxisome proliferator-activated receptor gamma and cardiovascular diseases. Circ J 2009; 73: 214-220.

11. Lim H, Dey SK. A novel pathway of prostacyclin signaling-hanging out with nuclear receptors. Endocrinology 2002; 143: $3207-$ 3210 .

12. Zhang J, Fu M, Zhu X, Xiao Y, Mou Y, Zheng H, et al. Peroxisome proliferator-activated receptor delta is up-regulated during vascular lesion formation and promotes post-confluent cell proliferation in vascular smooth muscle cells. J Biol Chem 2002; 277:
$11505-11512$

13. Lim HJ, Lee S, Park JH, Lee KS, Choi HE, Chung KS, et al. PPAR delta agonist L-165041 inhibits rat vascular smooth muscle cell proliferation and migration via inhibition of cell cycle. Atherosclerosis 2009; 202: 446-454.

14. Pola R, Gaetani E, Flex A, Aprahamian TR, Bosch-Marce M, Losordo DW, et al. Comparative analysis of the in vivo angiogenic properties of stable prostacyclin analogs: A possible role for peroxisome proliferator-activated receptors. J Mol Cell Cardiol 2004; 36: $363-370$.

15. Piqueras L, Reynolds AR, Hodivala-Dilke KM, Alfranca A, Redondo JM, Hatae T, et al. Activation of PPARbeta/delta induces endothelial cell proliferation and angiogenesis. Arterioscler Thromb Vasc Biol 2007; 27: 63-69.

16. Liou JY, Lee S, Ghelani D, Matijevic-Aleksic N, Wu KK. Protection of endothelial survival by peroxisome proliferator-activated receptor-delta mediated 14-3-3 upregulation. Arterioscler Thromb Vasc Biol 2006; 26: 1481-1487.

17. Tsai MC, Chen L, Zhou J, Tang Z, Hsu TF, Wang Y, et al. Shear stress induces synthetic-to-contractile phenotypic modulation in smooth muscle cells via peroxisome proliferator-activated receptor alpha/delta activations by prostacyclin released by sheared endothelial cells. Circ Res 2009; 105: 471-480.

18. Vila L. Cyclooxygenase and 5-lipoxygenase pathways in the vessel wall: Role in atherosclerosis. Med Res Rev 2004; 24: 399-424.

19. Reiss AB, Edelman SD. Recent insights into the role of prostanoids in atherosclerotic vascular disease. Curr Vasc Pharmacol 2006; 4: $395-408$.

20. Isogaya M, Yamada N, Koike H, Ueno Y, Kumagai H, Ochi Y, et al. Inhibition of resteNOSis by beraprost sodium (a prostaglandin $I_{2}$ analogue) in the atherosclerotic rabbit artery after angioplasty. J Cardiovasc Pharmacol 1995; 25: 947-952.

21. Numaguchi Y, Naruse K, Harada M, Osanai H, Mokuno S, Murase $\mathrm{K}$, et al. Prostacyclin synthase gene transfer accelerates reendothelialization and inhibits neointimal formation in rat carotid arteries after balloon injury. Arterioscler Thromb Vasc Biol 1999; 19: 727 733.

22. Arehart E, Stitham J, Asselbergs FW, Douville K, MacKenzie T, Fetalvero KM, et al. Acceleration of cardiovascular disease by a dysfunctional prostacyclin receptor mutation: Potential implications for cyclooxygenase-2 inhibition. Circ Res 2008; 102: 986-993.

23. Bunting S, Gryglewski R, Moncada S, Vane JR. Arterial walls generate from prostaglandin endoperoxides a substance (prostaglan$\operatorname{din} \mathrm{X}$ ) which relaxes strips of mesenteric and coeliac ateries and inhibits platelet aggregation. Prostaglandins 1976; 12: 897-913.

24. Murata T, Ushikubi F, Matsuoka T, Hirata M, Yamasaki A, Sugimoto, Y, et al. Altered pain perception and inflammatory response in mice lacking prostacyclin receptor. Nature 1997; 388: $678-682$.

25. Egan KM, Lawson JA, Fries S, Koller B, Rader DJ, Smyth EM, et al. COX-2-derived prostacyclin confers atheroprotection on female mice. Science 2004; 306: 1954-1957.

26. Kobayashi T, Tahara Y, Matsumoto M, Iguchi M, Sano H, Murayama T, et al. Roles of thromboxane A(2) and prostacyclin in the development of atherosclerosis in apoE-deficient mice. J Clin Invest 2004; 114: 784-794.

27. Thomas DW, Mannon RB, Mannon PJ, Latour A, Oliver JA, Hoffman M, et al. Coagulation defects and altered hemodynamic responses in mice lacking receptors for thromboxane $\mathrm{A}_{2}$. J Clin Invest 1998; 102: 1994-2001.

28. Dogne JM, Hanson J, Pratico D. Thromboxane, prostacyclin and isoprostanes: Therapeutic targets in atherogenesis. Trends Pharmacol Sci 2005; 26: 639-644.

29. Gleim S, Kasza Z, Martin K, Hwa J. Prostacyclin receptor/thromboxane receptor interactions and cellular responses in human atherothrombotic disease. Curr Atheroscler Rep 2009; 11: 227-235.

30. Masferrer JL, Zweifel BS, Manning PT, Hauser SD, Leahy KM, Smith WG, et al. Selective inhibition of inducible cyclooxygenase 2 in vivo is antiinflammatory and nonulcerogenic. Proc Natl Acad Sci USA 1994; 91: 3228-3232.

31. Baigent C, Patrono C. Selective cyclooxygenase 2 inhibitors, aspirin, and cardiovascular disease: A reappraisal. Arthritis Rheum 2003; 48: $12-20$.

32. Fosslien E. Cardiovascular complications of non-steroidal antiinflammatory drugs. Ann Clin Lab Sci 2005; 35: 347-385.

33. FitzGerald GA. COX-2 and beyond: Approaches to prostaglandin inhibition in human disease. Nat Rev Drug Discov 2003; 2: 879890.

34. Flavahan NA. Balancing prostanoid activity in the human vascular system. Trends Pharmacol Sci 2007; 28: 106-110. 
35. FitzGerald GA, Patrono C. The COXibs, selective inhibitors of cyclooxygenase-2. N Engl J Med 2001; 345: 433-442.

36. Baker CS, Hall RJ, Evans TJ, Pomerance A, Maclouf J, Creminon $\mathrm{C}$, et al. Cyclooxygenase-2 is widely expressed in atherosclerotic lesions affecting native and transplanted human coronary arteries and colocalizes with inducible nitric oxide synthase and nitrotyrosine particularly in macrophages. Arterioscler Thromb Vasc Biol 1999; 19: 646-655.

37. Schonbeck U, Sukhova GK, Graber P, Coulter S, Libby P. Augmented expression of cyclooxygenase-2 in human atherosclerotic lesions. Am J Pathol 1999; 155: 1281-1291.

38. Topper JN, Cai J, Falb D, Gimbrone MA Jr. Identification of vascular endothelial genes differentially responsive to fluid mechanical stimuli: Cyclooxygenase-2, manganese superoxide dismutase, and endothelial cell nitric oxide synthase are selectively up-regulated by steady laminar shear stress. Proc Natl Acad Sci USA 1996; 93: 10417-10422.

39. Smith LH, Boutaud O, Breyer M, Morrow JD, Oates JA, Vaughan DE. Cyclooxygenase-2-dependent prostacyclin formation is regulated by low density lipoprotein cholesterol in vitro. Arterioscler Thromb Vasc Biol 2002; 22: 983-988.

40. Caughey GE, Cleland LG, Penglis PS, Gamble JR, James MJ. Roles of cyclooxygenase (COX)-1 and COX-2 in prostanoid production by human endothelial cells: Selective up-regulation of prostacyclin synthesis by COX-2. J Immunol 2001; 167: 2831-2838.

41. Cook-Johnson RJ, Demasi M, Cleland LG, Gamble JR, Saint DA, James MJ. Endothelial cell COX-2 expression and activity in hypoxia. Biochim Biophys Acta 2006; 1761: 1443-1449.

42. Belton O, Byrne D, Kearney D, Leahy A, Fitzgerald DJ. Cyclooxygenase-1 and -2-dependent prostacyclin formation in patients with atherosclerosis. Circulation 2000; 102: 840-845.

43. Yamada M, Numaguchi Y, Okumura K, Harada M, Naruse K, Matsui $\mathrm{H}$, et al. Prostacyclin synthase gene transfer modulates cyclooxygenase-2-derived prostanoid synthesis and inhibits neointimal formation in rat balloon-injured arteries. Arterioscler Thromb Vasc Biol 2002; 22: 256-262.

44. Hansson GK, Libby P. The immune response in atherosclerosis: A double-edged sword. Nat Rev Immunol 2006; 6: 508-519.

45. Cipollone F, Prontera C, Pini B, Marini M, Fazia M, De Cesare D, et al. Overexpression of functionally coupled cyclooxygenase- 2 and prostaglandin $\mathrm{E}$ synthase in symptomatic atherosclerotic plaques as a basis of prostaglandin E(2)-dependent plaque instability. Circulation 2001; 104: 921-927.

46. Cipollone F, Rocca B, Patrono C. Cyclooxygenase-2 expression and inhibition in atherothrombosis. Arterioscler Thromb Vasc Biol 2004; 24: 246-255.

47. Cipollone F, Fazia M, Mezzetti A. Novel determinants of plaque instability. J Thromb Haemost 2005; 3: 1962-1975.

48. Burleigh ME, Babaev VR, Oates JA, Harris RC, Gautam S, Riendeau $\mathrm{D}$, et al. Cyclooxygenase-2 promotes early atherosclerotic lesion formation in LDL receptor-deficient mice. Circulation 2002; 105: 1816-1823.

49. Ristimaki A, Garfinkel S, Wessendorf J, Maciag T, Hla T. Induction of cyclooxygenase- 2 by interleukin-1 alpha: Evidence for post-transcriptional regulation. J Biol Chem 1994; 269: 11769-11775.

50. Arias-Negrete S, Keller K, Chadee K. Proinflammatory cytokines regulate cyclooxygenase-2 mRNA expression in human macrophages. Biochem Biophys Res Commun 1995; 208: 582-589.

51. Belton O, Fitzgerald D. Cyclooxygenase-2 inhibitors and atherosclerosis. J Am Coll Cardiol 2003; 41: 1820-1822.

52. Yatomi Y, Ozaki Y, Ohmori T, Igarashi Y. Sphingosine 1-phosphate: Synthesis and release. Prostaglandins 2001; 64: 107-122.

53. Nodai A, Machida T, Izumi S, Hamaya Y, Kohno T, Igarashi Y, et al. Sphingosine 1-phosphate induces cyclooxygenase-2 via $\mathrm{Ca}^{2+}$ dependent, but MAPK-independent mechanism in rat vascular smooth muscle cells. Life Sci 2007; 80: 1768-1776.

54. Rodriguez C, Gonzalez-Diez M, Badimon L, Martinez-Gonzalez J. Sphingosine-1-phosphate: A bioactive lipid that confers high-density lipoprotein with vasculoprotection mediated by nitric oxide and prostacyclin. Thromb Haemost 2009; 101: 665-673.

55. Rolland PH, Jouve R, Pellegrin E, Mercier C, Serradimigni A. Alteration in prostacyclin and prostaglandin $\mathrm{E}_{2}$ production: Correlation with changes in human aortic atherosclerotic disease. Arteriosclerosis 1984; 4: 70-78.

56. Kainoh M, Maruyama I, Nishio S, Nakadate T. Enhancement by beraprost sodium, a stable analogue of prostacyclin, in thrombomodulin expression on membrane surface of cultured vascular endothelial cells via increase in cyclic AMP level. Biochem Pharmacol 1991; 41: $1135-1140$.

57. Masferrer JL, Leahy KM, Koki AT, Zweifel BS, Settle SL, Woerner
$\mathrm{BM}$, et al. Antiangiogenic and antitumor activities of cyclooxygenase-2 inhibitors. Cancer Res 2000; 60: 1306-1311.

58. Pradono P, Tazawa R, Maemondo M, Tanaka M, Usui K, Saijo Y, et al. Gene transfer of thromboxane $\mathrm{A}(2)$ synthase and prostaglandin I(2) synthase antithetically altered tumor angiogenesis and tumor growth. Cancer Res 2002; 62: 63-66.

59. Hoper MM, Voelkel NF, Bates TO, Allard JD, Horan M, Shepherd $\mathrm{D}$, et al. Prostaglandins induce vascular endothelial growth factor in a human monocytic cell line and rat lungs via cAMP. Am J Respir Cell Mol Biol 1997; 17: 748-756.

60. Pueyo ME, Chen Y, D'Angelo G, Michel JB. Regulation of vascular endothelial growth factor expression by cAMP in rat aortic smooth muscle cells. Exp Cell Res 1998; 238: 354-358.

61. Smith OP, Battersby S, Sales KJ, Critchley HO, Jabbour HN. Prostacyclin receptor up-regulates the expression of angiogenic genes in human endometrium via cross talk with epidermal growth factor Receptor and the extracellular signaling receptor kinase $1 / 2$ pathway. Endocrinology 2006; 147: 1697-1705.

62. Murohara T, Horowitz JR, Silver M, Tsurumi Y, Chen D, Sullivan A, et al. Vascular endothelial growth factor/vascular permeability factor enhances vascular permeability via nitric oxide and prostacyclin. Circulation 1998; 97: 99-107.

63. Hiraoka K, Koike H, Yamamoto S, Tomita N, Yokoyama C, Tanabe T, et al. Enhanced therapeutic angiogenesis by cotransfection of prostacyclin synthase gene or optimization of intramuscular injection of naked plasmid DNA. Circulation 2003; 108: 26892696.

64. Koike H, Morishita R, Iguchi S, Aoki M, Matsumoto K, Nakamura $\mathrm{T}$, et al. Enhanced angiogenesis and improvement of neuropathy by cotransfection of human hepatocyte growth factor and prostacyclin synthase gene. Faseb J 2003; 17: 779-781.

65. Wheeler-Jones C, Abu-Ghazaleh R, Cospedal R, Houliston RA, Martin J, Zachary I. Vascular endothelial growth factor stimulates prostacyclin production and activation of cytosolic phospholipase A2 in endothelial cells via p42/p44 mitogen-activated protein kinase. FEBS Lett 1997; 420: 28-32.

66. He H, Venema VJ, Gu X, Venema RC, Marrero MB, Caldwell RB. Vascular endothelial growth factor signals endothelial cell production of nitric oxide and prostacyclin through flk-1/KDR activation of c-Src. J Biol Chem 1999; 274: 25130-25135.

67. Krishnamurthy P, Bird IM, ShePPARd C, Magness RR. Effects of angiogenic growth factors on endothelium-derived prostacyclin production by ovine uterine and placental arteries. Prostaglandins Other Lipid Mediat 1999; 57: 1-12.

68. Matsumoto K, Morishita R, Tomita N, Moriguchi A, Yamasaki K, Aoki M, et al. Impaired endothelial dysfunction in diabetes mellitus rats was restored by oral administration of prostaglandin $I_{2}$ analogue. J Endocrinol 2002; 175: 217-223.

69. Higashi Y, Noma K, Yoshizumi M, Kihara Y. Endothelial function and oxidative stress in cardiovascular diseases. Circ J 2009; 73: 411-418.

70. Niwano K, Arai M, Tomaru K, Uchiyama T, Ohyama Y, Kurabayashi $M$. Transcriptional stimulation of the eNOS gene by the stable prostacyclin analogue beraprost is mediated through cAMP-responsive element in vascular endothelial cells: Close link between PGI signal and NO pathways. Circ Res 2003; 93: 523-530.

71. Niwano K, Arai M, Koitabashi N, Hara S, Watanabe A, Sekiguchi $\mathrm{K}$, et al. Competitive binding of CREB and ATF2 to cAMP/ATF responsive element regulates eNOS gene expression in endothelial cells. Arterioscler Thromb Vasc Biol 2006; 26: 1036-1042.

72. Asahara T, Murohara T, Sullivan A, Silver M, van der Zee R, Li T, et al. Isolation of putative progenitor endothelial cells for angiogenesis. Science 1997; 275: 964-967.

73. Walter DH, Rittig K, Bahlmann FH, Kirchmair R, Silver M, Murayama T, et al. Statin therapy accelerates reendothelialization: A novel effect involving mobilization and incorporation of bone marrow-derived endothelial progenitor cells. Circulation 2002; 105: 3017-3024.

74. Werner N, Junk S, Laufs U, Link A, Walenta K, Bohm M, et al. Intravenous transfusion of endothelial progenitor cells reduces neointima formation after vascular injury. Circ Res 2003; 93: e17-e24.

75. Takahashi T, Kalka C, Masuda H, Chen D, Silver M, Kearney M, et al. Ischemia- and cytokine-induced mobilization of bone marrowderived endothelial progenitor cells for neovascularization. Nat Med 1999; 5: 434-438.

76. Takakura N, Watanabe T, Suenobu S, Yamada Y, Noda T, Ito Y, et al. A role for hematopoietic stem cells in promoting angiogenesis. Cell 2000; 102: 199-209.

77. Miyahara Y, Ohnishi S, Obata H, Ishino K, Sano S, Mori H, et al. Beraprost sodium enhances neovascularization in ischemic myo- 
cardium by mobilizing bone marrow cells in rats. Biochem Biophys Res Commun 2006; 349: 1242-1249.

78. Otsuka H, Akashi H, Murohara T, Okazaki T, Shintani S, Tayama $\mathrm{K}$, et al. The prostacyclin analog beraprost sodium augments the efficacy of therapeutic angiogenesis induced by autologous bone marrow cells. Ann Vasc Surg 2006; 20: 646-652.

79. Di Stefano R, Barsotti MC, Melillo E, Iorio M, Santoni T, Armani $\mathrm{C}$, et al. The prostacyclin analogue iloprost increases circulating endothelial progenitor cells in patients with critical limb ischemia. Thromb Haemost 2008; 100: 871-877.

80. Asai J, Takenaka H, Katoh N, Kishimoto S. Dibutyryl cAMP influences endothelial progenitor cell recruitment during wound neovascularization. J Invest Dermatol 2006; 126: 1159-1167.

81. He T, Lu T, d'Uscio LV, Lam CF, Lee HC, Katusic ZS. Angiogenic function of prostacyclin biosynthesis in human endothelial progenitor cells. Circ Res 2008; 103: 80-88.
82. Kawabe JI, Yuhki KI, Okada M, Kanno T, Yamauchi A, Tashiro, $\mathrm{N}$, et al. Prostaglandin I 2 promotes recruitment of endothelial progenitor cells and limits vascular remodeling. Arterioscler Thromb Vasc Biol 2010; 30: 464-470.

83. Sainz J, Sata M. When endothelial progenitor cell says $\mathrm{I}_{2}$ shall limit neiointima formation! Arterioscler Thromb Vasc Biol 2010; 30: 457-458.

84. He T, Peterson TE, Katusic ZS. Paracrine mitogenic effect of human endothelial progenitor cells: Role of interleukin-8. Am J Physiol Heart Circ Physiol 2005; 289: H968-H972.

85. Santhanam AV, Smith LA, He T, Nath KA, Katusic ZS. Endothelial progenitor cells stimulate cerebrovascular production of prostacyclin by paracrine activation of cyclooxygenase-2. Circ Res 2007; 100: $1379-1388$.

86. Shantsila E, Watson T, Lip GY. Endothelial progenitor cells in cardiovascular disorders. J Am Coll Cardiol 2007; 49: 741 -752. 